\title{
Highway wind power energy assessment of Al-Durra highway street in Baghdad, Iraq
}

\author{
Adnan Ahmed Abdul Raheem, Wadhah Esmaeel Ibraheem \\ Technical Institute of Ba'aqubah, Middle Technical University, Bagdad, Iraq
}

\begin{tabular}{l} 
Article Info \\
\hline Article history: \\
Received Feb 2, 2020 \\
Revised Apr 26, 2020 \\
Accepted Jun 10, 2020 \\
\hline Keywords: \\
Wind energy \\
Highway wind energy \\
VAWT \\
Renewable Energy \\
Small wind turbines
\end{tabular}

Article Info

Revised Apr 26, 2020

Accepted Jun 10, 2020

Highway wind energy

Renewable Energy

\begin{abstract}
In certain spots on the planet which have less attainable of utilizing enormous breeze power plants, the expressway wind vitality can be utilized to help little loads in the main grids. Interstates road lighting for instance of that heaps that is expending a great deal of vitality and cost every year. When the vitality that originates from vehicles development along the highway avenues can be taken in thought, this paper has examined the outcomes if moment vehicles wind speed during 24 hours per day. 24 hours, brief interim of vehicles wind speeds have been estimated by utilizing anemometer put in the road. A vertical pivot wind turbine (VAWT) has been proposed to be utilized in this task. All venture regulation has been simulated by utilizing Opendss program; it can support time series simulation. The outcomes demonstrated that the undertaking is possible to be utilized in Al-Durra Highway Street. The normal breeze speed of moving vehicles is $4.7 \mathrm{~m} / \mathrm{s}$ which can deliver 67.3 watt by the proposed turbine. The got energy saw that it as contributed to be utilized by the maingrid during the day time. All the demonstrated bends of the outcomes speak to the Iraq grid support by diminishing the main demand and operational expenses too.
\end{abstract}

This is an open access article under the CC BY-SA license.

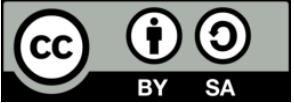

\section{Corresponding Author:}

Adnan Ahmed Abdul Raheem,

Technical Institute of Ba'aqubah,

Middle Technical University, Bagdad, Iraq.

Email: adnan.alsumeri@mtu.edu.iq

\section{INTRODUCTION}

The increasing demand of worldwide to electrical energy and the fears from lost every source of fossil fuel in the world because the fossil fuel like oil, gas and coal may exist to several decades but not for the far future [1,2], this issues guide the worldwide to the concept of renewable energy, the renewable energy solve this two problems because of it is friendly to environment mean does not create carbon emission and it is sustainable energy source like solar energy, wind energy, geothermal energy and bioenergy [3] and will not run out. The wind energy is one of them; to harvesting the wind energy will use many kinds and sizes of wind turbine. This type of resources are providing $4.8 \%$ of global energy, where $564 \mathrm{GW}$ have been installed in 2018 over the world increasing by $10 \%$ of growth [4]. The principle operation of wind turbine it is generated the electricity from the wind, traditional turbine content of three blades, the passing of wind over the blades will drive the shift which goes to gearbox which increase the rotation speed of shift to generate electricity by using the magnetic fields, the generated electricity was transmitted to grid and distributed around the country. When the wind speed be around 3-4 meters per seconds $(\mathrm{m} / \mathrm{s}),(8$ miles per hour $)$, most of wind turbine started to generated the electricity; maximum power generated when the wind speed be around $15(\mathrm{~m} / \mathrm{s})(30 \mathrm{mph})$, when the wind speed reach to $25(\mathrm{~m} / \mathrm{s})$, or more than $(50 \mathrm{mph})$ the generate will be stop to prevent the turbine from the damage [5]. 
There is paper using vertical axis wind turbine (VAWT) install on the side of the highway on king Fahad Bin Abdul Aziz highway in Kuwait, the data was collected at 10 different test, the average harvesting of wind speed is $4.4 \mathrm{~m} / \mathrm{s}$ [6]. There is another study in [3] it uses the two different shape of vehicles, one of the shape of vehicles is a sedan and the second one is a bus, then analysis and study what the effect of moving the different shape of vehicles on the generated of wind speed subsequently generated the power. The tandem cars case gives the maximum power enhancement. This concept has been discussed and evaluated in the study was done in 2016, where the results showed the power the power which is produced by wind turbines is limited by the vehicles types and how they move as a lone or as groups [7] .some of studies are using a hybrid design to power the street lights, the system consists of renewable resources like PV panels with wind turbines and battery with controller; the results showed that wind energy in which reduced the requirement of storage about $38 \%$ with $14.4 \%$ cost reduction, this study can support this paper encouragement of using these type of wind turbines in Al-Durra highways [8]. In india an effective study has been done and $64 \%$ of maximum rotational speed was achieved if small wind turbines were used along highways streets[9]. According to that VAWT wind turbine will be used along median strip of Highway Street in Baghdad/Iraq, harvesting the wind speed it is come from vehicles movement along the highway to feeding the VAWT turbine to generating the electricity and supplying the street lighting at night.

\section{METHODOLOGY}

The wind energy of highway generation comes from the feeling of the power at the side of any highway in the world. Al-Durra Highway Street is very active in Iraq, the intensity of the vehicle's movement is almost during all the day and night. The speed of the wind there depends on the speed and shape of vehicles. The power generation depends on the vehicles speed proportionally [10]. The proposal of work is distributing small vertical axis turbines (VAWT) with battery along median strip of Al-Durra Highway Street to generate electricity. The cause of using VAWT types of wind turbines is due to their efficiency of high speed wind collecting, as well as the high starting capacity of torque [8,9].This electricity is used to charge batteries and supply the street lighting at night.

\subsection{Data gethering}

In this paper, wind speeds have been evaluated by using UT-632 wind speed meter (Anemometer). This device is citified by Uni-Trend Company [13]. One minute interval has been collected for 24 hours per day with two levels 2 and 3 meters. 24 hours per day has been tested to show the wind speed that is generated by moving vehicles in Al-Durra Highway Street. The proposed vertical axis wind turbine (VAWT) in this paper is the a small one which is investigated in the study with parameters below [14].

\subsection{Wind turbine modeling}

The wind turbine generators are devices that convert the mechanical energy of wind speed to the electrical power. The generated electricity can be stored to the batteries or can be injected to the distributed grids as on-grids networks, and optimize the normal operation of the system[15]. The kinetic energy of the turbine relies on the mechanical design of the blades, rotor and the air density of area of project installation. The proposed design to the Al-Durra Highway Street is shown in Figure 1.

The turbine design of the project can be installing three blades on lighting rods of the Al-Durra Highway Street. Each blade has a $0.8 \mathrm{~m}$ width and $1.8 \mathrm{~m}$ height dimensional parameters as being an acceptable swept area. All together are connected by bearing converts the rotation to an AC permanent magnet generator which delivers electricity that need to converted to high quality DC voltage to be used for batteries charging. The mechanical power of the project can be estimated by (1) below [16].

$$
\mathrm{P}_{m}=0.5 \rho \mathrm{A} \mathrm{V}^{3}
$$

Where is

$\mathrm{P}$ is a mechanical power in watt

$\rho$ is a wind density in $\mathrm{kg} / \mathrm{m}^{3}$

$\mathrm{A}$ is the cross section area of each blade (swept area) in $\mathrm{m}^{2}$

$\mathrm{V}$ is the wind speed in $\mathrm{m} / \mathrm{s}$

The electrical power can also extracted by the equation above through the wind turbine efficiency, where this efficiency can be expressed by a collection of variables that are determined by taking the design, wind resistance and turbulence as a factors and explained with limit called Betz limit [17, 18]. The (2) below can be used to represent the electrical power in terms of object efficiency. 


$$
\mathrm{P}_{\mathrm{w}}=\frac{\mathrm{P}_{\mathrm{m}}}{\mathrm{Cp}}
$$

Theatrically, the maximum value of the power coefficient is 0.5926 ; in this paper Cp is considered as a maximum value to simulate the output power of the proposed wind generators. The theoretical output power electricity in terms of the wind speed manner can be showed in the Figure 2, where is the power started to be generated gradually in proportional value with the speed of the wind. As shown the power converted to be constant at wind speed equal to $9 \mathrm{~m} / \mathrm{s}$ and the generator starts to deliver electricity at $3 \mathrm{~m} / \mathrm{s}$, those values are called the rated speed and cut-in speed respectively and they translation of installed motor in the design.

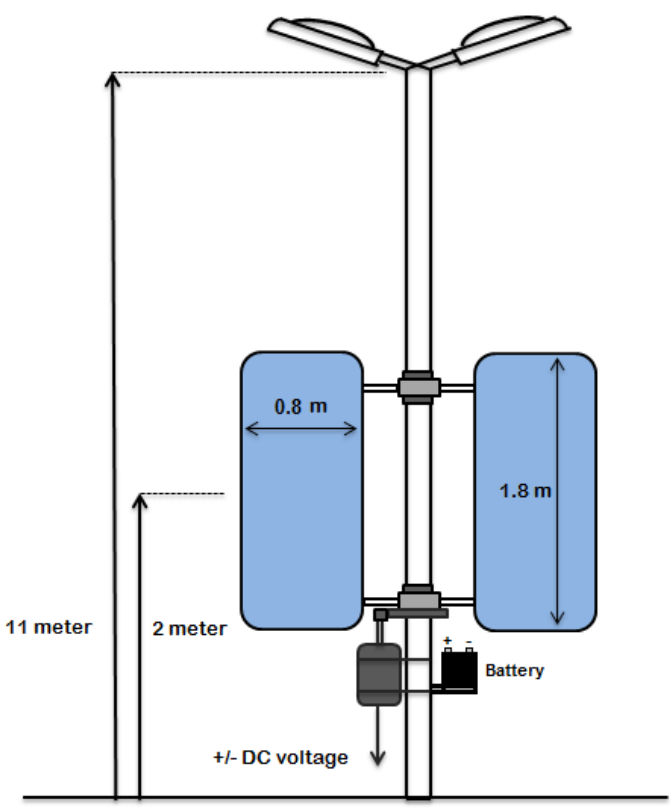

Figure 1. Proposed VAWT design for Al-Durra highway street number of blades $=3$

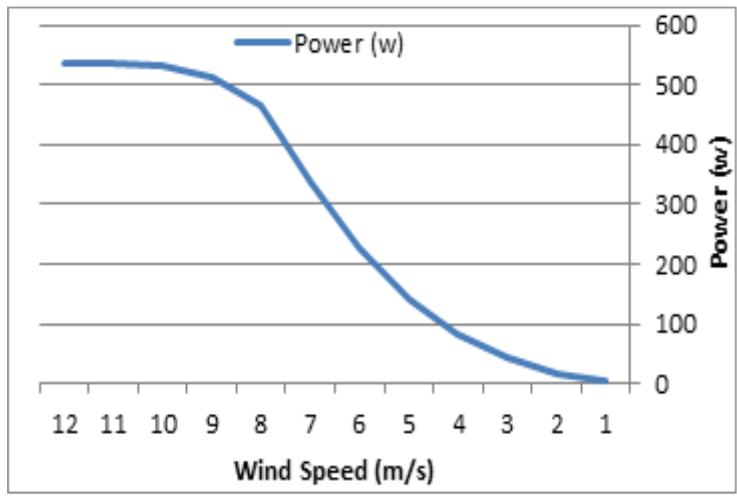

Figure 2. The theoretical output power of proposed VAWT generator

\subsection{Battery modeling}

In this paper a $200 \mathrm{Ah}, 12 \mathrm{~V}$ battery has been collected and suggested to be installed in every pole along the street. This capacity delivers power to the load during the night. The modeling has been done by using OpenDss simulator. The proposed simulation executed at the AC side of the inverter according to the program properties and command bellow.



These parameters give a highly benefits to the main grid of the distribution system as will be shown in the results later.

\subsection{The project configuration}

Al-Durra Highway Street passes through many vital areas of Baghdad and is equipped with a light and the two sides along the road with a distance of $13 \mathrm{~km}$. It is connected between Mohammed Elqassim and Baghdad Roads as shown in Figure 3. The design standards of street lighting are $50 \mathrm{~m}$ between each two poles. The poles are installed in the median strip of the way and everyone is equipped with two lamps lighting the both sides. Each bulb has a rated power about $400 \mathrm{w}$, with approximately 2.25 ampere. The daily power consumption of this configuration is very high, and recently due to this issue; the operation cost can be 
large as well. The operation time of the street lighting is 13 hours in the winter and 10 hours in the summer, the average is 11 hours per day especially Iraqi winter is shorter than summer [19]. The overall demand consumption of the lights during the night is $208 \mathrm{~kW}$, where road is lighted by 520 bulb work all together. According to that and to the last year pricing of the electricity demand in Iraq [20], the Al-Durra Highway Street consumes 9.2 million Iraqi dinnar per year approximately. The Table 1 represents the information above. In this paper the suggested wind turbine topology and changing the lights to $100 \mathrm{~W}$ light emitted diode (LED) will reduce the consumption and operation cost which represent a kind of country support and development[21].

Table 1. Al-Durra highway street lighting information

\begin{tabular}{lc}
\hline Variable & Detail \\
\hline Al-Durra Highway Street length & $13 \mathrm{~km}$ \\
Lighting poles span & $50 \mathrm{~m}$ \\
Number of poles along the street & 260 \\
Number of bulbs (2/pole) & 520 \\
Rated power for bulb (watt) & $400 \mathrm{w}$ \\
Overall power demand of the street (watt) & $208 \mathrm{~kW}$ \\
\hline
\end{tabular}

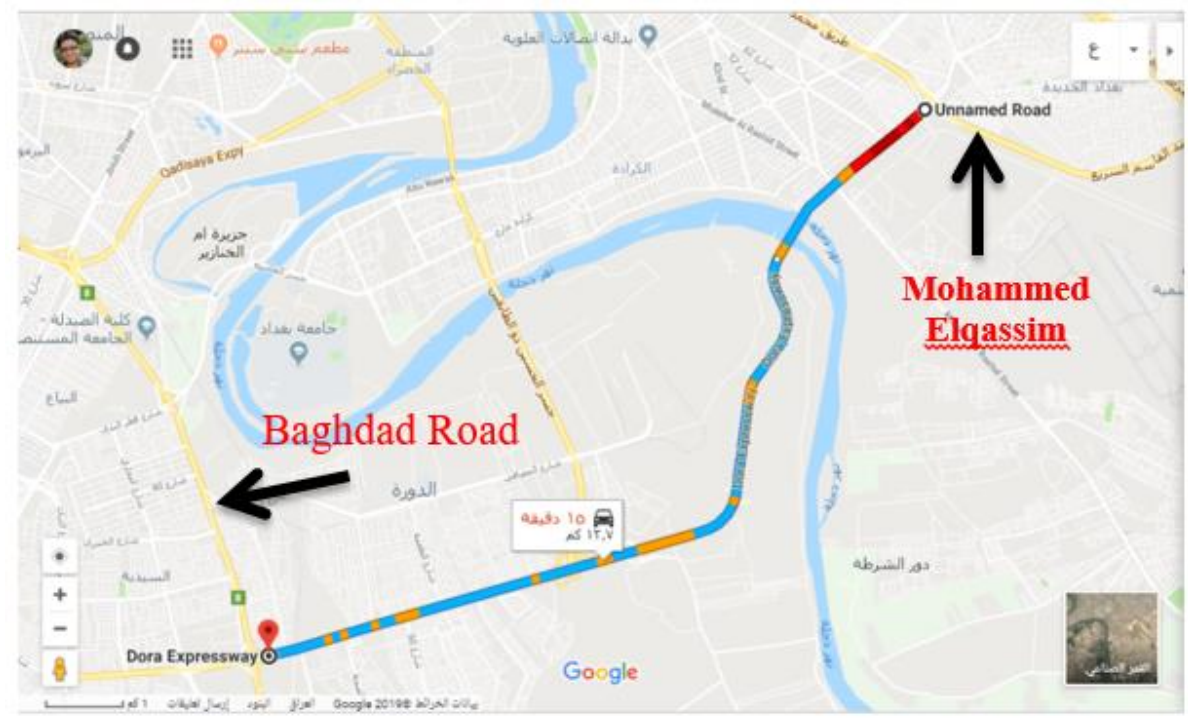

Figure 3 The Google map of Al-Durra highway street [22]

\section{RESULTS AND DISCUSSION}

According to the proposed design, the results that have been obtained were feasible. Where the current which is generated by moving vehicles in Al-Durra express highway street was generating power along the day time and night. The energy can be used into two ways, one of them is charging the battery when the energy level is low, and then the rest of the energy when the battery is full, can be reversed to the distribution grid to be consumed by the customers. Based to the field measurements was fluctuated between minimum value $(1.4 \mathrm{~m} / \mathrm{s})$ and maximum value $(9.8 \mathrm{~m} / \mathrm{s})$ at two meter high level. As shown in the Figure 4, the manner of the curve has an average equal to $4.7 \mathrm{~m} / \mathrm{s}$ which can generate about 67.3 watt eventually.

Accordingly, the generated power by the proposed design was shown in the Figure 5 where the power also fluctuates due to the variation of wind speed that changed according to the many factors like the vehicle's velocity and shape and size as well. The energy during the day is assumption of the obtained results and equal to $2.8 \mathrm{kWh}$ per day. This energy can contribute with the main supply to charge the installed battery, beside to deliver power to the public electricity grid when the battery is full. 


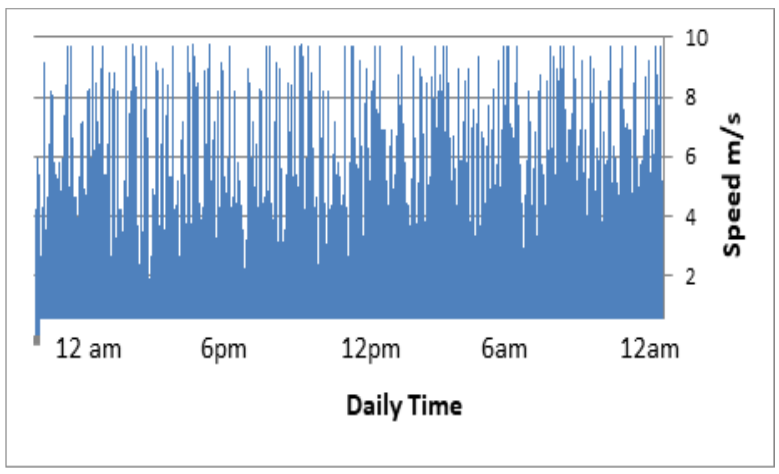

Figure 4 Daily wind speed profile $(\mathrm{m} / \mathrm{s})$

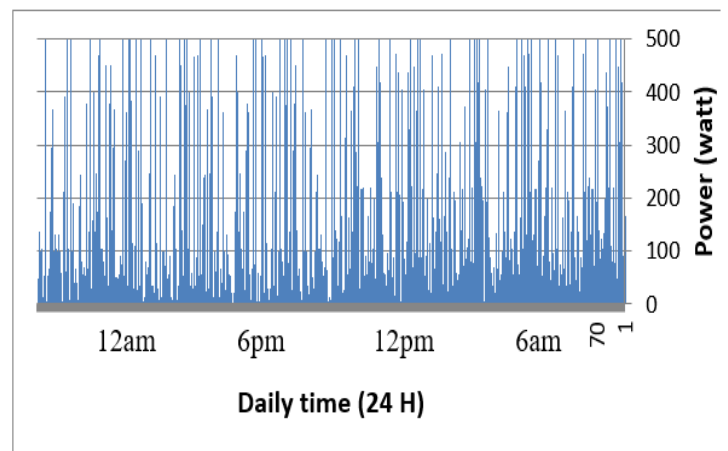

Figure 5 Daily wind generator power (W)

As shown in Figure 6 the curve 1 represents the consumed power by the lighting system in the highway road without the proposed model. The curve shows that the power is delivered according to the lighting daily demand. The offline time is between $6 \mathrm{am}$ to $6 \mathrm{pm}$. And when the suggested system is connected without battery, the consumed power could be less due to the delivered energy by the wind generator as shown in curve 2 . Where it shows that the wind generation can reduce $1 \mathrm{~kW}$ power from main grid, and beside of that the continuous power which is delivered by the wind generator can be reversed to the distribution system through the main supply line. And when we connect the battery to the system the results show that the lights are full supplied by the battery during the night time, a little of energy can be needed from the public electricity to charge the battery as support with wind energy as shown in curve 3 during the time from 6 am to $1 \mathrm{pm}$.

It is worth mentioning that the height of turbine can affect directly to the wind generation. This paper had examined the vehicle wind speed at 3 meter height. The wind speed at this altitude is less efficient than the height of 2 meters; where a mean of $1.4 \mathrm{~m} / \mathrm{s}$ was obtained for the total readings that were tested for three specific hours during the day. Therefore, the appropriate height was chosen in this project for the best production of the wind energy produced from the street is 2 meters. The Figure 7 shows the real comparison between the two heights and the same place and the same hours chosen. The red curve represent to the wind speed at 2 meters which is fluctuated between $2-11 \mathrm{~m} / \mathrm{s}$; where the blue one is belong to the wind speed at 3 meters which is fluctuated between $0-3 \mathrm{~m} / \mathrm{s}$. obviously, the quantity of energy power can be produced more if the turbines would be installed at 2 meters height.

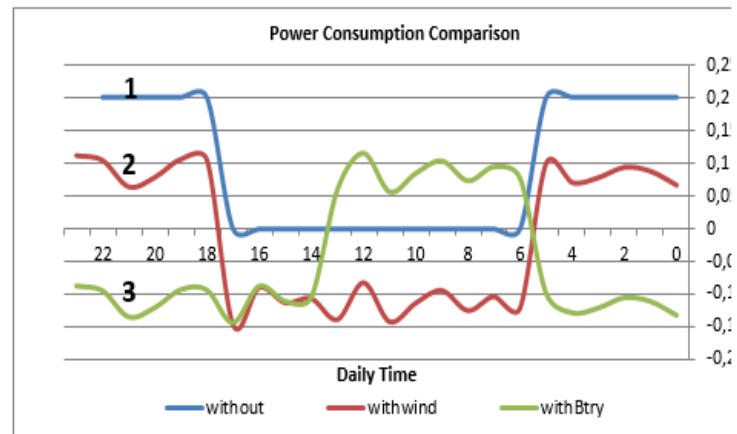

Figure 6. Charging and consumption of the battery current status

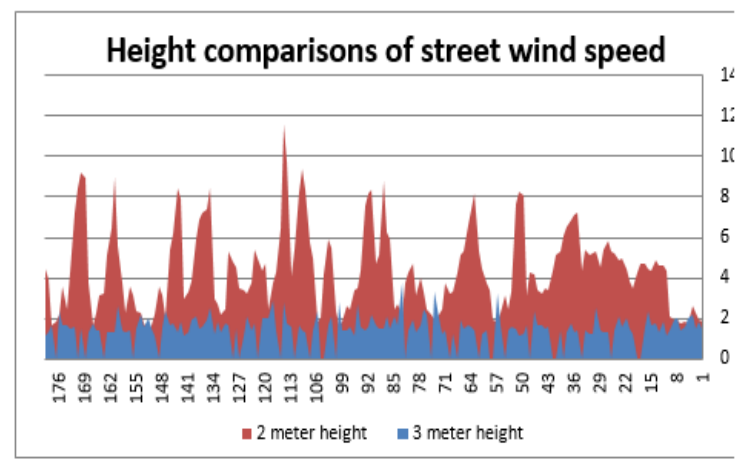

Figure 7.Height comparisons of street wind speed

\section{CONCLUSION}

This paper has tested the vehicle velocity in the Al-Durra Highway Street. The study has found that the average wind speed during the day and night time is about $4.7 \mathrm{~m} / \mathrm{s}$ at (2) two meters height level. This average can generate a proper energy to charge the battery and supply the electricity to the grid under micro grids connection project. A 500 watt wind turbine design has been modeled; this power rating can deliver 2.8 $\mathrm{kW}$ per day. The obtained energy can share with the main supply to maintain the battery level is full along 
the 24 hours, the time of day time is considered charging time according the obtained data and this time is enough to return the battery to be full again. The environmental conditions and designing operation can effect directly to the project generation. This paper has tested another height level in the same conditions. Six hours per day has been compared, then it found the energy at (3) three meter height level is less efficient than lower height. According to the obtained results, the project can support the government and the main distribution in terms of operation cost and supplying distribution grid.

\section{REFERENCES}

[1] N. Abas, A. Kalair, and N. Khan. "Review of fossil fuels and future energy technologies." Futures, vol. 69, pp. 31-49, 2015

[2] Y. Kumar et al. "Wind energy: Trends and enabling technologies." Renew. Sustain. Energy Rev., vol. 53, pp. 209-224, 2016.

[3] X. Cao, X. Dai, and J. Liu. "Building energy-consumption status worldwide and the state-of-the-art technologies for zero-energy buildings during the past decade." Energy Build., vol. 128, pp. 198-213, 2016.

[4] WWEA. "World Wide Energy Association." 2019. [Online]. Available: https://wwindea.org/blog/2020/04/16/world-wind-capacity-at-650-gw/.

[5] E. Europe wind energy association. "Wind Energy-The Facts." An Analysis of Wind Energy in the EU-25, Executive Summary, 2016. [Online]. Available: http://www.ewea.org/. [Accessed: 02-Jul-2019].

[6] E. H. Bani-Hani, A. Sedaghat, M. Al-Shemmary, A. Hussain, A. Alshaieb, and H. Kakoli. "Feasibility of Highway Energy Harvesting Using a Vertical Axis Wind Turbine.” Energy Eng. J. Assoc. Energy Eng., vol. 115, no. 2, pp. 61-74, 2018.

[7] C. Lapointe, S. Hall, U. Street, H. Gopalan, S. Hall, and U. Street. "Numerical Investigation of Mini Wind Turbines near Highways.” J. Sol. Energy Eng., vol. 138, pp. 1-4, 2016.

[8] W. R. Nyemba et al. "Optimization of the design and manufacture of a solar-wind hybrid street light." Procedia Manuf., vol. 35, pp. 285-290, 2019.

[9] S. Santhakumar, I. Palanivel, and K. Venkatasubramanian. "A study on the rotational behaviour of a Savonius Wind turbine in low rise highways during different monsoons." Energy Sustain. Dev., vol. 40, pp. 1-10, 2017.

[10] W. Hu et al. "Effect analysis on power coefficient enhancement of a convective wind energy collecting device in the expressway." Energy Convers. Manag. vol. 171, pp. 249-271, 2018.

[11] B. Sindhuja. "A Proposal for Implementation of Wind Energy Harvesting System in Trains." 2014 Int. Conf. Control. Instrumentation, Energy Commun., pp. 696-702, 2014

[12] S. N. Malave and S. P. Bhosale. "Highway Wind Turbine ( Quite Revolution Turbine )." Int. J. Eng. Res. Technol., vol. 6, no. 6, pp. 789-794, 2013.

[13] “Anemometer UNI-T UT362 USB :: UNI-T." [Online]. Available: https://www.uni-t.cz/en/p/anemometer-uni-tut362-usb. [Accessed: 11-Feb-2019].

[14] S. R. Shah, R. Kumar, K. Raahemifar, and A. S. Fung. "Design, modeling and economic performance of a vertical axis wind turbine." Energy Reports, vol. 4, pp. 619-623, 2018.

[15] O. Zebraoui and M. Bouzi. "Improved MPPT controls for a standalone PV/wind/battery hybrid energy system." Int. J. Power Electron. Drive Syst., vol. 11, no. 2, pp. 988-1001, 2020.

[16] M. Pushpavalli, N. M. J. Swaroopan, and A. Info. "Performance analysis of hybrid photovoltaic/wind energy system using KY boost converter.” Int. J. Power Electron. Drive Syst., vol. 10, no. 1, pp. 433-443, 2019.

[17] H. Y. Peng, H. F. Lam, and H. J. Liu. "Power performance assessment of H-rotor vertical axis wind turbines with different aspect ratios in turbulent flows via experiments." Energy, vol. 173, pp. 121-132, 2019.

[18] Z. Li, P.-F. Gao, and T.-T. Sun. "A new power generation calculation method for vertical axis wind turbine control." in 2015 International Conference on Machine Learning and Cybernetics (ICMLC), pp. 200-204, 2015.

[19] "Sunrise and sunset times in Baghdad." [Online]. Available: https://www.timeanddate.com/sun/iraq/baghdad. [Accessed: 20-Feb-2019].

[20] "Ministry of

of Electricity,"

2019.

[Online].

Available: https://www.moelc.gov.iq/index.php?name=Pages\&op=page\&pid=269. [Accessed: 20-Feb-2019].

[21] K. Shahzad et al. "An ecological feasibility study for developing sustainable street lighting system Kingdom of Saudi Arabia." J. Clean. Prod., vol. 175, p. 683e695, 2018.

[22] "Dora Expressway, Baghdad to Mohammed Elqassim Road, Baghdad -Google Maps." [Online]. Available: https://www.google.iq/maps/dir/33.3019606,44.4662193/Dora+Expressway,+Baghdad/@33.2644822,44.3935381, 12.92z/data $=! 4 \mathrm{~m} 8 ! 4 \mathrm{~m} 7 ! 1 \mathrm{~m} 0 ! 1 \mathrm{~m} 5 ! 1 \mathrm{~m} 1 ! 1 \mathrm{~s} 0 x 1559 \mathrm{~d} 51 \mathrm{c} 540 \mathrm{f} 5 \mathrm{c} 1 \mathrm{f}: 0 x e 44 \mathrm{ed} 23 \mathrm{ff} 3 \mathrm{~d} 138 \mathrm{~b} 8 ! 2 \mathrm{~m} 2 ! 1 \mathrm{~d} 44.373577 ! 2 \mathrm{~d} 33.237$ 6577. [Accessed: 16-Feb-2019]. 


\section{BIOGRAPHIES OF AUTHORS}

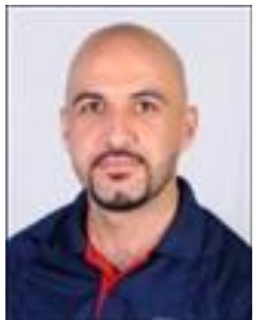

Adnan Ahmed Abdulraheem received his master of electrical engineering from Acharya Nagarjuna University, india (ANU) in 2016. Prior to this he had graduated his first degree from Department of Electrical Engineering. Al-Furat Al-Awsat University, Technical Collage of AlMussaib (2011-2012) Now he is an assist lecturer in Technical Institute of Ba' aqubah, Middle Technical University, Iraq. His research interests lie predominantly in the area of renewable sources of energy.

Email: adnan.alsumeri@mtu.edu.iq

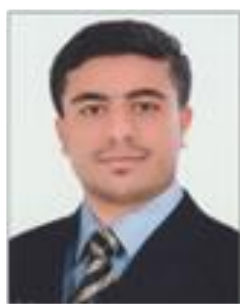

Wadhah Esmaeel Ibraheem received his master of electrical engineering from Universiti Teknikal Malaysia Melaka (UTeM) in 2014. Prior to this he had graduated his first degree from Department of Electrical Engineering, University of Diyala in Iraq (2005-2009). Now he is an assist lecturer in Technical Institute of Ba'aqubah, Middle Technical University, Iraq. His research interests lie predominantly in the area of renewable sources of energy and the Impact of PV system in distribution grids.

Email: wadhah.esmaee187@ mtu.edu.iq 